\title{
The Lighter Side
}

Send contributions to

The Lighter Side to

the editor (address on

the inside front cover).

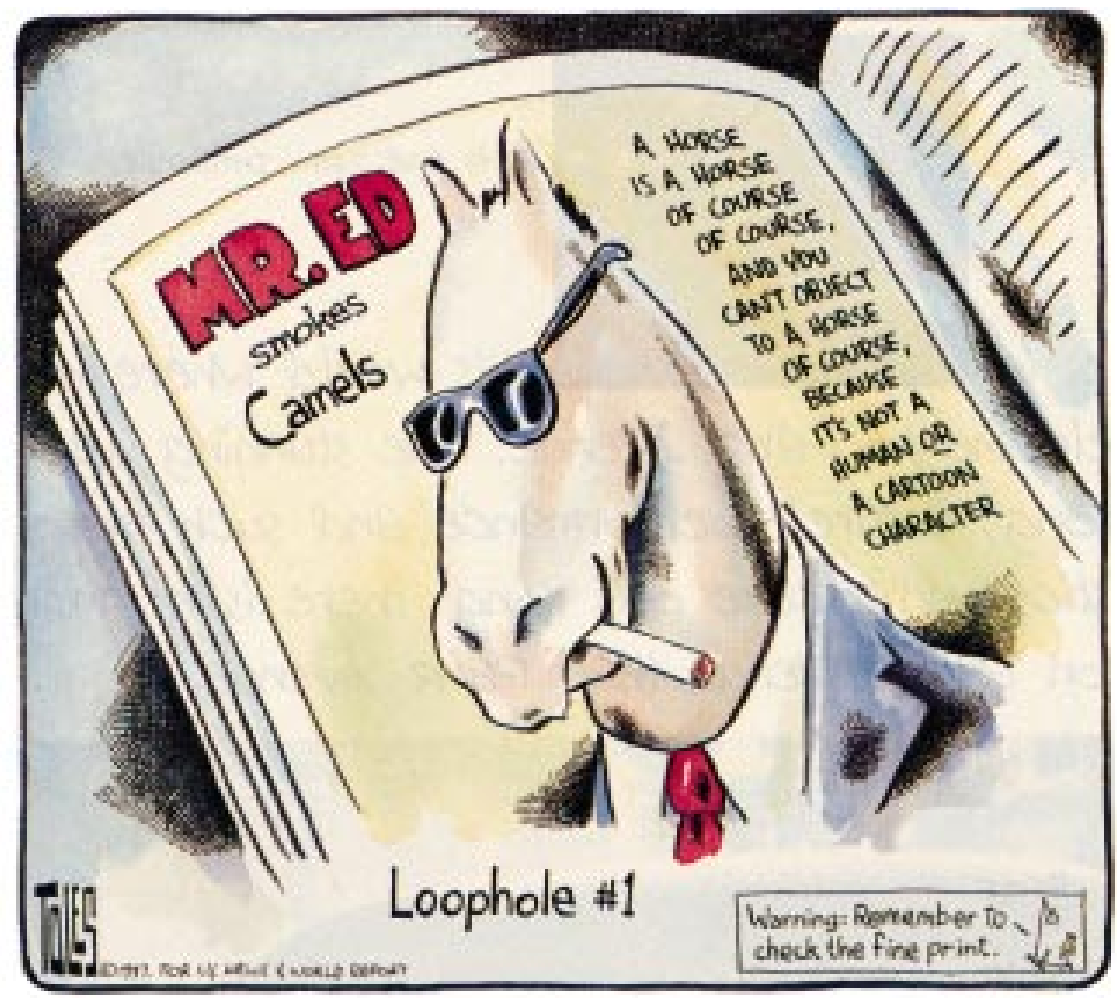

TOLES (C) 1997 “The Buffalo News”, reprinted by permission of Universal Press Syndicate. All rights reserved. (The proposed tobacco industry settlement agreement would ban the use of human models and cartoon characters in tobacco advertising, but would allow other types of imagery in "adult" publications. - ED)
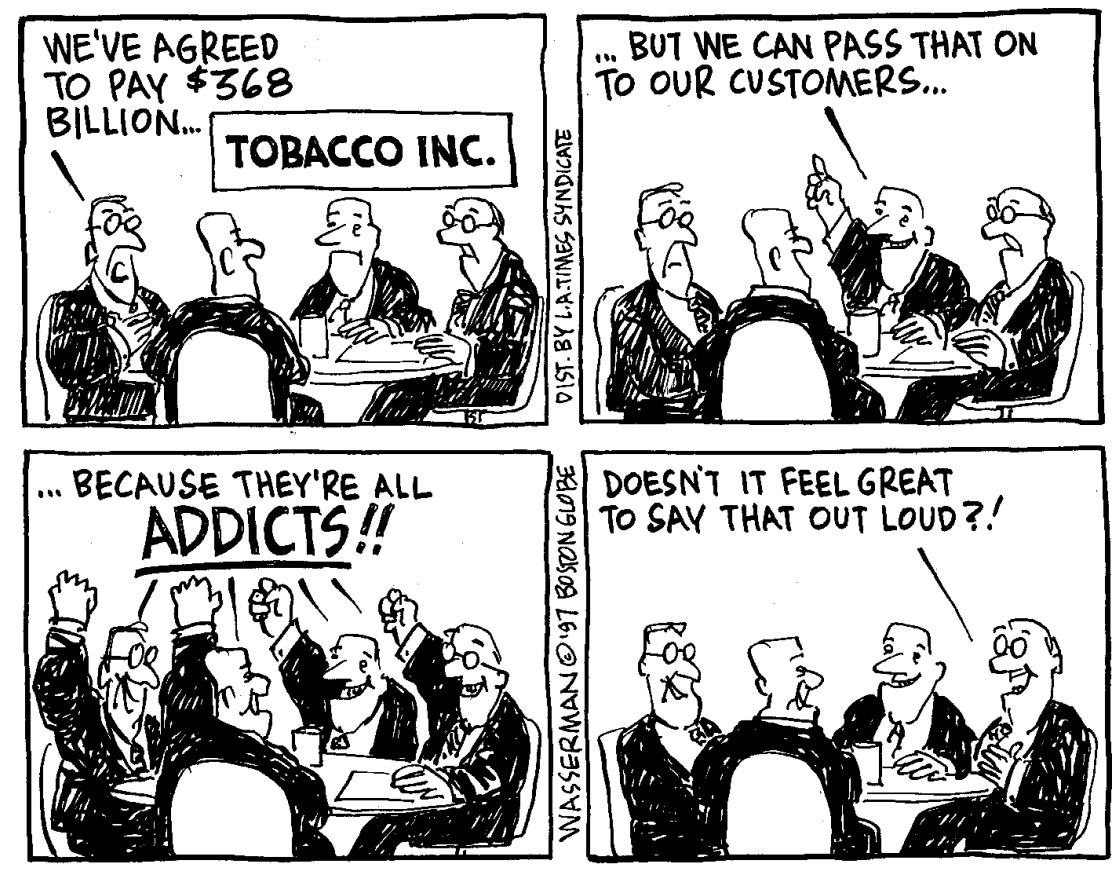

By Dan Wasserman of the "Boston Globe", (C) 1997. Reprinted by permission of the Los Angeles Times Syndicate. 

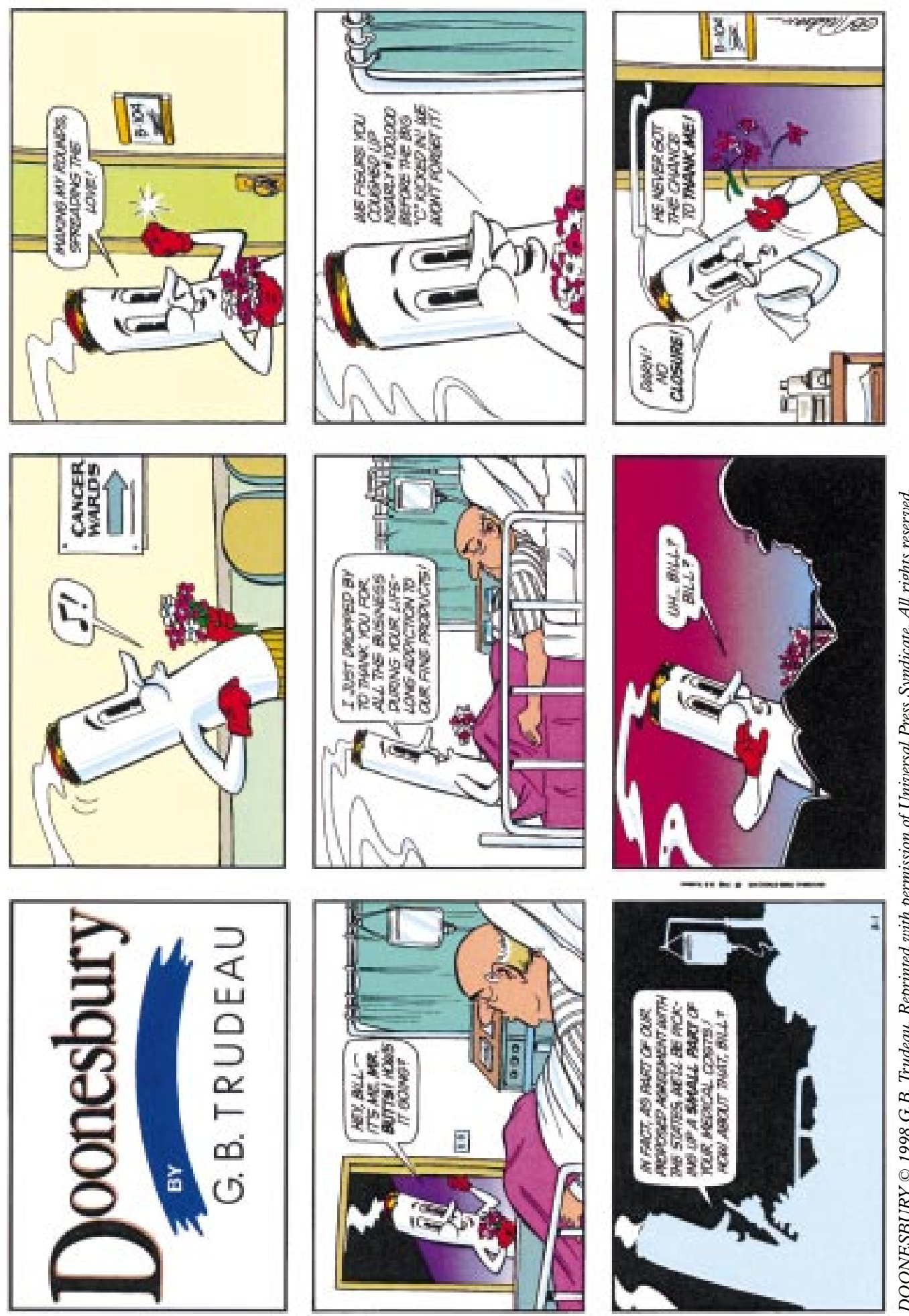

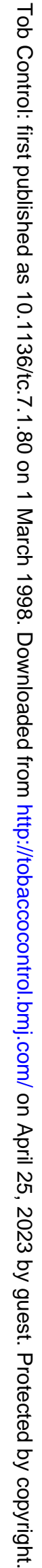

